\title{
The Advantage of a Dedicated STEM for High-Resolution Structural and Chemical Analysis of Li-Ions Batteries Electrode Materials
}

\author{
M.L. Trudeau*, R. Veillette* and K. Zaghib** \\ * Materials Science, Hydro-Québec Research Institute, 1800 Boul. Lionel-Boulet, Varennes, \\ Québec, Canada, J3X 1S1 \\ ** Energy Storage and Conversion, Hydro-Québec Research Institute, 1800 Boul. Lionel-Boulet, \\ Varennes, Québec, Canada, J3X 1S1
}

Li-ion batteries are emerging as one of the most promising technology for energy storage today. To increase the overall battery performance, different materials are presently being investigated to improve on the properties of the anode and cathode in used today. However, it is now well acknowledged that for both electrodes the materials need to be designed at the nanometric level. In order to correctly understand the macroscopic properties of these nanocomposites functionalized materials, together with electrochemical performance analysis, it is essential to perform complete characterization of their structure, as well at the chemical nature of the different species present, at the sub-nanometer level. In this presentation, we will show some recent results of high-resolution structural and chemical analysis of new electrodes materials design to improve the properties of lithium ion batteries. The high resolution characterization was done using a Hitachi HD-2700C dedicated STEM with a CEOS aberration corrector and a cold field emission gun, equipped with a newly designed SDD EDS detector from Bruker. This dedicated STEM has demonstrated an image resolution of $78 \mathrm{pm}$ in HAADF. One of the main advantages of this system is that this unique combination of a cold emitter, CEOS corrector and SDD detector allows for very fast EDS elemental analysis with the real possibility of elemental mapping at the nanometer or even subnanometer level. Such a tool is critical for the present technological race in the development of new electrode materials that will be found in the next generation of batteries.

At the present time, $\mathrm{LiFePO}_{4}$ is widely view as the new preferred cathode for lithium batteries because it is a non toxic and low cost material. In this presentation, we will show results of high resolution transmission electron microscopy studies of the structural transformations happening during the synthesis of carbon coated $\mathrm{LiFePO}_{4}(\mathrm{C}-\mathrm{LiFePO}) . \mathrm{Li}_{2} \mathrm{CO}_{3}, \mathrm{FePO}_{4}$ powders or low cost precursors such $\mathrm{Fe}, \mathrm{LiOH}, \mathrm{H}_{3} \mathrm{PO}_{4}$ where mixed together with the addition of a polymer compound or a carbon precursor. Observations of the structural transformation from room temperature to $900{ }^{\circ} \mathrm{C}$ and the formation of $\mathrm{LiFePO}_{4}$ were realized in the HD-2700 operated at $200 \mathrm{kV}$ under vacuum [1]. Figure-1 presents dark field micrographs of one of these precursor powders at different temperatures, revealing that the major morphological changes are happening around $700{ }^{\circ} \mathrm{C}$. Furthermore, detailed chemical characterization of new nanocomposite materials will be described. As an example, Figure- 2 presents a dark and bright field micrographs of a $\mathrm{LiFePO}_{4} / \mathrm{LiMnPO}_{4}$ nanocomposite and Figure-3 clearly show the nutshell structure of this new material, with a $\mathrm{LiFePO}_{4}$ layer clearly surrounding a $\mathrm{LiMnPO}_{4}$ crystalline center.

${ }^{[1]}$ The authors would like to acknowledge the assistance of D. Laul from Hitachi High Technologies for some samples observation. 
Fig. 1 Dark field STEM micrographs of a mixture of $\mathrm{Li}_{2} \mathrm{CO}_{3}, \mathrm{FePO}_{4}$ and a polymer at a) Room Temperature, b) $500{ }^{\circ} \mathrm{C}$, c) $600{ }^{\circ} \mathrm{C}$ and d) $700^{\circ} \mathrm{C}$.

a)

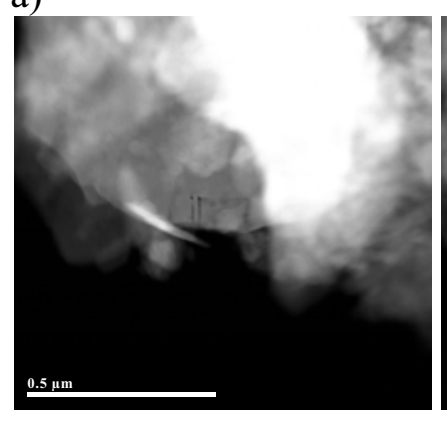

b)

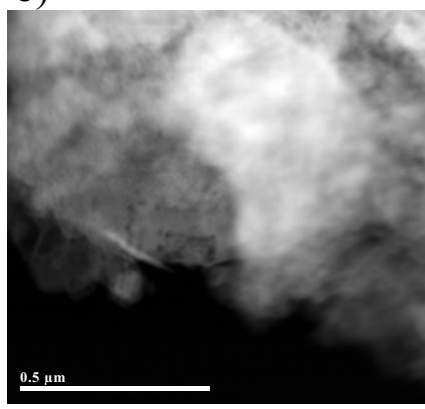

c)

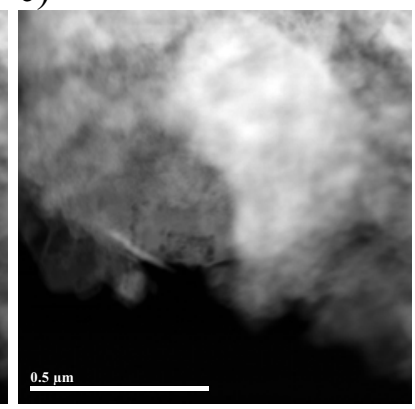

d)

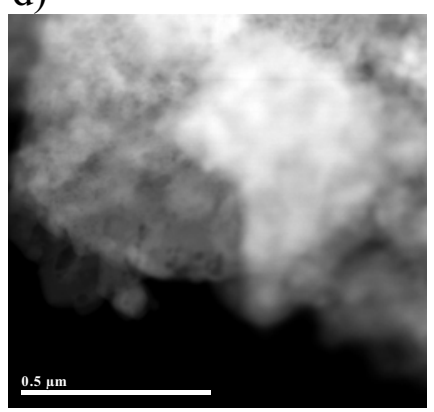

Fig. 2 a) Dark and b) Bright field STEM micrographs of $\mathrm{LiFePO}_{4} / \mathrm{LiMnPO}_{4}$ nanocomposite powders.
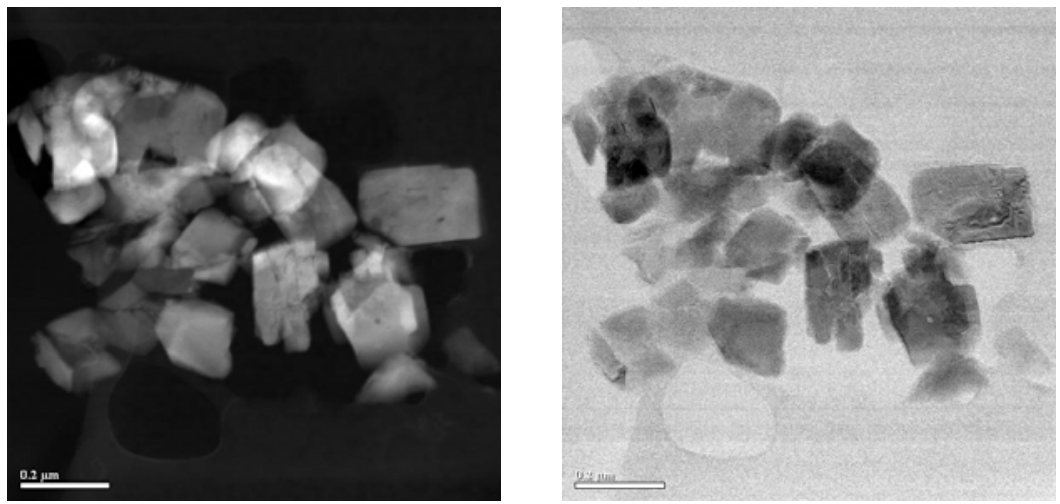

Fig. 3 EDS mapping of $\mathrm{LiFePO}_{4} / \mathrm{LiMnPO}_{4}$ nanocomposites powders showing clearly the nutshell structure of a $\mathrm{LiMnPO}_{4}$ center surrounded by a $\mathrm{LiFePO}_{4}$ crystalline layer.
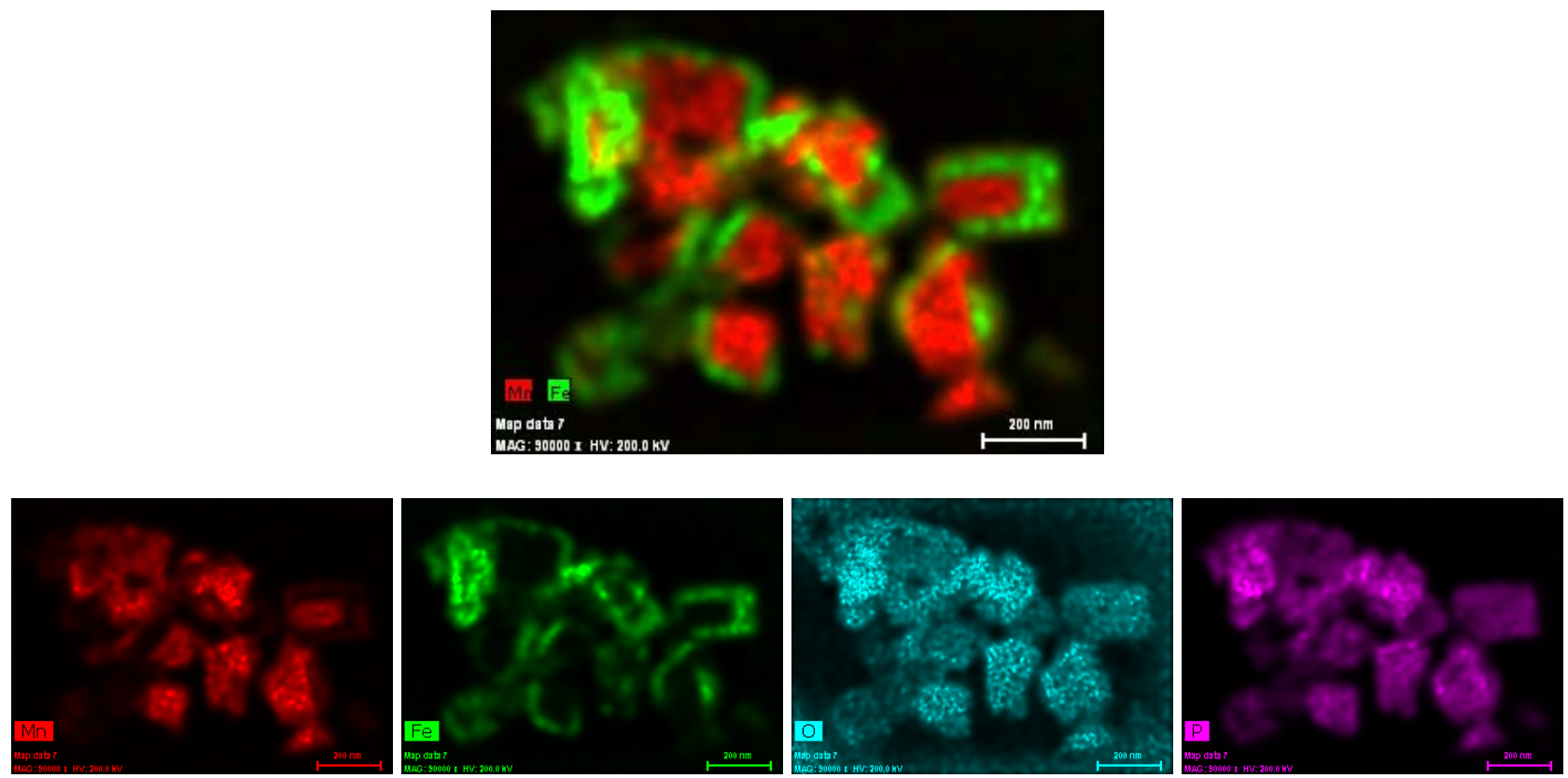